\title{
25 Research Square

\section{Functional Outcome in Cats with Acute Severe Injuries of the Thoracolumbar Spinal Cord Following Intensive Rehabilitative Physiotherapy}

Antonella Gallucci ( $\square$ antonella.gallucci@tiscali.it)

Private Practice https://orcid.org/0000-0002-5772-2712

Ludovica Dragone

Dog Fitness centre

Tania Al Kafaji

Universita di Bologna

Marika Menchetti

San Marco Veterinary Clinic, Neurology and Neurosurgery Division (PD)

Sara Del Magno

Universita di Bologna

Gualtiero Gandini

Universita di Bologna

Research article

Keywords: thoracolumbar (TL), pain perception (PP)

Posted Date: July 24th, 2020

DOI: https://doi.org/10.21203/rs.3.rs-47933/v1

License: (c) (1) This work is licensed under a Creative Commons Attribution 4.0 International License.

Read Full License 


\section{Abstract}

Background: literature is lacking data concerning the prognosis in cat suffering from acute thoracolumbar spinal cord lesions on field condition either with or without physiotherapy treatment. We investigated the role of intensive physical rehabilitation training in cats suffering from acute thoracolumbar (TL) spinal cord injury and compared their outcome to the presence/absence of pelvic limb pain perception (PP) under field conditions. A further aim was the evaluation of the outcome of cats under intensive physiotherapy when compared to a control group.

Methods: Retrospective study. The medical records of 29 feline patients with acute TL spinal cord injury, with and without PP, selected for intensive rehabilitation treatment were reviewed. Those cats that satisfied the same criteria, but performed at home physiotherapy exercises with the owner, were enrolled as control group.

Results: 7 cats had pelvic limb PP, which resulted significantly associated with functional recovery of voluntary locomotion $(p=0.01)$ and voluntary micturition $(p=0.00006)$. Twenty-two cats $(76 \%)$ had the absence of pelvic limb PP and the acquisition of spinal walking (SW) was achieved in ten cats (45\%). None of these patients regained a voluntary micturition at the end of the treatment. The presence of the crossed extensor reflex on admission was significantly associated with the acquisition of SW $(p=0.008)$. At 15 days, improvement in assisted walking/UWTM was found to be significantly associated with higher possibility to achieve SW at the end of the treatment $(p=0.04)$. The control group included seven cats. None of the cats had regained voluntary micturition or ambulatory condition. Comparing to the control group, the intensive rehabilitation program was significantly associated with a higher possibility to regain functional locomotion $(p=0.005)$. Recovery of voluntary micturition did not show significant differences among the control group and the cats that underwent physical therapy.

Conclusions: cats with severe acute TL lesion recovery can benefit from physiotherapy and, also in case of loss of PP, the acquisition of SW is possible under field condition.

\section{Background}

The use of physical therapy in veterinary medicine is gradually increasing in the last decade and several studies described its role in the outcome of dogs with thoracolumbar (TL) intervertebral disk herniation (IVDH) [1-6]. In cats, many studies were performed under experimental conditions and showed the usefulness of treadmill activity in promoting recovery of motor function in cats after incomplete and complete spinal cord lesions [7-9].

Rehabilitation seems to have the best beneficial role in dogs with a functionally complete spinal cord lesion and highlights the possibility to achieve an involuntary reflex gait, commonly described as spinal walking (SW) [5]. The acquisition of SW is made possible by dynamic interactions between the pelvic limb central pattern generator (CPG) and proprioceptive feedback from the body in absence of a superior control by the brain after a complete spinal cord (SC) lesion [10, 11]. 
To the author's knowledge, veterinary literature is lacking data related to the role of rehabilitation in TL cats in field conditions. This study aimed to retrospectively investigate the results of an intensive physical rehabilitation treatment in cats suffering from acute TL spinal cord injury and compare their outcome to the presence/absence of pelvic limb pain perception (PP) under field conditions. Further aim was the evaluation of the outcome of cats under intensive physiotherapy treatment when compared to a control group.

\section{Methods}

A retrospective study was conducted on feline patients with acute TL spinal cord injury referred to the Physiotherapy and Rehabilitation Centre "Dog Fitness" (Reggio Emilia, Italy) between 2006 and 2017. Cats were considered eligible for the study if they satisfied the following 3 criteria:

1. Presence of complete clinical records including physical examination data and neurological status, assessed by neurological examination performed at admission and at the end of the treatment.

2. Diagnosis of acute TL spinal cord lesion, confirmed by survey radiography of the spine (in case of external trauma) or Advanced Imaging Techniques (Magnetic Resonance Imaging or Computed Tomography)

3. Availability of data regarding the physiotherapy protocol performed.

Cats with spinal cord acute injury between C1-T2 or caudal to L3, feline patients with chronic spinal cord damage and cats without adequate information were excluded from the study.

Cats that satisfied only criteria 1 and 2, but performed at home physiotherapy exercises with the owner, were enrolled in the study as control group. In the control group, data regarding further improvement were collected through recorded follow-up neurological consultations or interviewing the owners by phone at the time of this study. Cats without a minimum of a 3-month follow-up were excluded.

The rehabilitation program was established and personalized by the physiotherapist for each patient and included the following basic categories of exercises: passive range of motion (ROM) exercises, flexor reflex and crossed extensor reflex stimulation, active-assisted exercises and hydrotherapy with Under Water Treadmill (UWTM). Cats underwent 45-60 minutes of physiotherapy treatment, twice daily, seven days per week regardless of their status of hospitalization. Cats reluctant to be trained in UWTM because afraid of water, in 4 days became increasingly confident through the exposition to a minimum water level, slowly progressively increased to reach the height of the cat's greater trochanter, considered the optimal water level by the physiotherapist.

The overall rehabilitation duration was established for each cat according to the physiotherapist's decision on whether to continue or stop the treatment based on the patient's improvement of the neurological condition. 
For each cat enrolled, specific parameters were evaluated at the time of admission and at days 15 and, if still included in the study, at days 45, 90. They included: breed, sex, age, Body Condition Score (BCS), clinical presentation, type of lesion, pain perception, voluntary micturition, presence of surgery, hospitalization during the treatment, time between onset of signs and the start of rehabilitation, duration of physical therapy.

The study population was divided in two groups according to the presence or absence of PP (PP group and NoPP Group respectively). PP was assessed applying heavy forceps pressure to the pelvic limb digits. The lack of patient's conscious response (e.g. turning in the direction of the applied stimulus or similar reactions) was interpreted as absence of PP. Paraplegic TL cats without PP, at the admission and during the whole treatment, were further classified in two sub-groups based on the acquisition of an autonomous reflex gait: the spinal walking group (SW-group) and no spinal walking group (No SWgroup). Feline patients were defined as Spinal Walker if they could walk for a potentially infinite period of time and, in case of falling, they were able to regain unassisted standing posture and continue to walk [5].

\section{Statistics}

Statistical analysis was conducted using commercial software for scientific data analysis (Past ${ }^{\circledR}$, version 3.17). Shapiro-Wilk test was used to verify the normal data distribution and Chi-square test to analyze parametric and non-parametric variables. P-value $<0.05$ was considered to be statically significant.

To identify potential variables associated to the recovery of motor function, the following parameters were considered for each patient at 15, 45, 90 days of follow up: breed, sex, age, BCS, clinical presentation, type of lesion, voluntary micturition, presence of surgery, hospitalization during the treatment, time between onset of signs and the start of rehabilitation, duration of physical therapy and maintenance of PP.

To investigate potential factors related to the possibility of achieving SW, within the NoPP group the presence or absence of crossed extensor reflex was evaluated.

Finally, to evaluate the potential role of an intensive rehabilitation program, the outcome of population study and cats of the control group were compared.

\section{Results}

Medical records of sixty cats admitted to the physiotherapy center with a spinal cord injury were retrospectively reviewed. Twenty-nine cats met the inclusion criteria and were enrolled in the study (Fig. 1). Seven cats were included in the control group.

Data regarding signalment, type of lesion, neurologic signs, delay in the onset of physiotherapy and duration of the rehabilitation program are detailed in Table 1. 
Table 1

Study population.

\begin{tabular}{|lll|}
\hline Cats & & 29 \\
\hline Breed & European shorthair & $\mathrm{n}=25(86 \%)$ \\
\hline Age & Other & $\mathrm{n}=4(14 \%)$ \\
\hline Sex & $\mathrm{m} 24$ months (range 1-168) & \\
\hline & Male & $\mathrm{M} \mathrm{n}=10(83 \%) \mathrm{C}=2$ \\
\hline & Female & $(17 \%)$ \\
\hline BCS & $\mathrm{m} 5$ (range 4-8) & $\mathrm{F} \mathrm{n}=12(71 \%) \mathrm{N}=5$ (29\%) \\
\hline Type of lesion & Spinal vertebral trauma & $\mathrm{n}=21(73 \%)$ \\
\hline & Acute disc herniation & $\mathrm{n}=5(17 \%)$ \\
\hline Cats with full-time hospitalization & Contusive/hemorrhagic SC & $\mathrm{n}=3(10 \%)$ \\
\hline Cats undergoing spinal surgery & & $\mathrm{n}=17(59 \%)$ \\
\hline Delay in onset of physiotherapy* & $\mathrm{m} 32$ days (range 3-900 days) & $\mathrm{n}=3(34 \%)$ \\
\hline $\begin{array}{l}\text { Duration of rehabilitation } \\
\text { program }\end{array}$ & $\mathrm{m}$ 47 days (range 15-302) & \\
\hline *Days between the onset of early signs and the beginning of physical therapy \\
\hline m, median value; C, castrated; $\mathrm{N}$, neutered; BCS, body condition score, SC spinal cord
\end{tabular}

All patients received physical therapy for a minimum of 15 days. Follow-up data obtained from recorded neurological examinations at 45 and 90 days were available for $19(66 \%)$ and $8(27 \%)$ cats, respectively (Table 2). 
Table 2

Follow-up at 15, 45, 90 days and end of treatment in the PP-Group and No-PP Group.

\begin{tabular}{|c|c|c|c|c|}
\hline & & $\begin{array}{l}\text { Cats under } \\
\text { intensive } \\
\text { physiotherapy } \\
\text { treatment }\end{array}$ & $\begin{array}{l}\text { Cats that stopped the treatment } \\
\text { because recovered voluntary } \\
\text { motor function (PP group) or } \\
\text { acquired SW (No PP group) }\end{array}$ & $\begin{array}{l}\text { Cats that stopped } \\
\text { rehabilitation } \\
\text { program for owner's } \\
\text { decision or absence } \\
\text { of improvement }\end{array}$ \\
\hline \multirow[t]{2}{*}{15 Days } & $\begin{array}{l}\text { PP- } \\
\text { Group }\end{array}$ & 7/7 (100\%) & 0/7 (0\%) & $0 / 7(0 \%)$ \\
\hline & $\begin{array}{l}\text { No- } \\
\text { PP } \\
\text { Group }\end{array}$ & $22 / 22(100 \%)$ & $0 / 22(0 \%)$ & $0 / 22(0 \%)$ \\
\hline \multirow[t]{2}{*}{45 Days } & $\begin{array}{l}\text { PP- } \\
\text { Group }\end{array}$ & $6 / 7$ (86\%) & $1 / 7(14 \%)$ & $0 / 7(0 \%)$ \\
\hline & $\begin{array}{l}\text { No- } \\
P P \\
\text { Group }\end{array}$ & $13 / 22(59 \%)$ & $3 / 22(14 \%)$ & $6 / 22(27 \%)$ \\
\hline \multirow[t]{2}{*}{90 Days } & $\begin{array}{l}\text { PP- } \\
\text { Group }\end{array}$ & $3 / 7(43 \%)$ & $3 / 7(43 \%)$ & $0 / 7(0 \%)$ \\
\hline & $\begin{array}{l}\text { No- } \\
\text { PP } \\
\text { Group }\end{array}$ & $5 / 22(23 \%)$ & $4 / 22$ (18\%) & $4 / 22(18 \%)$ \\
\hline \multirow{3}{*}{$\begin{array}{l}\text { End of } \\
\text { treatment }\end{array}$} & Tot & & $7 / 7(100 \%)$ & $0 / 7(0 \%)$ \\
\hline & Group & & $10 / 22$ (45\%) & $12 / 22(55 \%)$ \\
\hline & $\begin{array}{l}\text { Tot } \\
\text { No- } \\
\text { PP } \\
\text { Group }\end{array}$ & & & \\
\hline
\end{tabular}

\section{PP Group}

Seven cats (24\%) had pelvic limb PP at the time of presentation and during the whole treatment. All of them recovered motor function at the end of the rehabilitation program (100\%). Pelvic limb PP was significantly associated with functional recovery of voluntary locomotion $(p=0.01)$ and voluntary micturition $(p=0.00006)$.

At the time of the first examination, five cats $(71 \%)$ showed a non-ambulatory paraparesis while the other two $(29 \%)$ had ambulatory paraparesis. Micturition dysfunction affected three cats $(43 \%)$ and, at the end of the treatment, two of them $(67 \%)$ recovered voluntary micturition.

Spinal trauma was reported in five patients $(71 \%)$ while the other two cats were affected by disc herniation (29\%). Two cats (29\%) had full-time hospitalization. Surgery, aimed to the stabilization of the 
spine after the trauma, was performed in two cases (29\%). The time between the onset of clinical signs and the beginning of rehabilitation ranged from 3 to 271 days with a median of 44 days. The median duration of physiotherapy treatment was 58 days (range 19-206) (Table 3 ).

Table 3

Summary of clinical data of the PP group of cats

\begin{tabular}{|c|c|c|c|}
\hline & & FR cats $(n=7)$ & $\begin{array}{l}\text { No FR cats }(n= \\
0)\end{array}$ \\
\hline \multirow[t]{2}{*}{ Type of lesion } & Spinal trauma & $\mathrm{n}=5(71 \%)$ & - \\
\hline & $\begin{array}{l}\text { Acute disc } \\
\text { herniation }\end{array}$ & $\mathrm{n}=2(29 \%)$ & - \\
\hline Full-time hospitalization & & $\mathrm{n}=2(29 \%)$ & - \\
\hline Cats undergoing surgery & & $\mathrm{n}=2(29 \%)$ & - \\
\hline $\begin{array}{l}\text { Delay in onset of physiotherapy* } \\
\text { (days) }\end{array}$ & & $\begin{array}{l}m=44 \text { (range } 3- \\
271)\end{array}$ & - \\
\hline $\begin{array}{l}\text { Duration of rehabilitation program } \\
\text { (days) }\end{array}$ & & $\begin{array}{l}m=58 \text { (range } 19- \\
206)\end{array}$ & - \\
\hline
\end{tabular}

\section{NoPP Group}

Twenty-two cats $(76 \%)$ had absence of pelvic limb PP at the time of initial presentation and during the whole treatment. On admission, all patients were paraplegic and, at that time, eight cats (36\%) already showed the presence of some involuntary movements. Incompetent bladder was present in all cats and partial reflex bladder emptying was reported in three of them (14\%). At the end of rehabilitation treatment, the acquisition of autonomous spinal locomotion (SW) was achieved in ten cats (45\%), while none of the patients regained a voluntary micturition.

Sixteen cats (73\%) were affected by spinal trauma (vertebral fracture/luxation). Three cats $(14 \%)$ had an acute disc herniation and three (14\%) a contusive/hemorrhagic lesion of the spinal cord. Fifteen patients (68\%) were hospitalized and surgery, aimed to stabilization of the spine, was performed in eight cats $(36 \%)$. Delay in the onset of physical therapy ranged from 5 to 900 days and the median value was 20 days. The median duration of the rehabilitation program was 46 days (range 15-302 days). Crossed extensor reflex was observed in sixteen cats $(73 \%)$ soon after the beginning of the physiotherapy.

Clinical and follow-up data of the NoPP-group cats, expressed according to the acquisition/no acquisition of SW, are detailed in Tables 4 and 5, respectively. 
Table 4

Summary of clinical data of the NoPP group of cats

\begin{tabular}{|c|c|c|c|}
\hline & & SW cats $(n=10)$ & $\begin{array}{l}\text { No SW cats }(n= \\
12)\end{array}$ \\
\hline \multirow[t]{3}{*}{ Type of lesion } & Spinal trauma & $\mathrm{n}=6(60 \%)$ & $n=10(84 \%)$ \\
\hline & Acute disc herniation & $\mathrm{n}=2(20 \%)$ & $\mathrm{n}=1(8 \%)$ \\
\hline & $\begin{array}{l}\text { Contusive/hemorrhagic } \\
\text { lesion }\end{array}$ & $\mathrm{n}=2(20 \%)$ & $\mathrm{n}=1(8 \%)$ \\
\hline Full-time hospitalization & & $n=6(60 \%)$ & $\mathrm{n}=9(75 \%)$ \\
\hline Cats undergoing surgery & & $\mathrm{n}=4(40 \%)$ & $\mathrm{n}=4(33 \%)$ \\
\hline $\begin{array}{l}\text { Delay in onset of } \\
\text { physiotherapy* (days) }\end{array}$ & & $\begin{array}{l}m=26 \text { (range } 7- \\
900)\end{array}$ & $\begin{array}{l}m=19 \text { (range } 5- \\
730)\end{array}$ \\
\hline $\begin{array}{l}\text { Duration of rehabilitation } \\
\text { program (days) }\end{array}$ & & $\begin{array}{l}m=52 \text { (range } \\
18-302 \text { ) }\end{array}$ & $\begin{array}{l}m=46 \text { (range } \\
15-204)\end{array}$ \\
\hline $\begin{array}{l}\text { Crossed extensor reflex at } \\
\text { admission }\end{array}$ & & $\mathrm{n}=8(80 \%)$ & $\mathrm{n}=6(50 \%)$ \\
\hline $\begin{array}{l}\text { *Days between the onset } \\
\text { Spinal Walking; No SW, N }\end{array}$ & $\begin{array}{l}\text { s and the beginning } \\
\text { lking }\end{array}$ & ysical therapy; & dian value; SW, \\
\hline
\end{tabular}


Table 5

Follow-up at 15, 45, 90 days after initiation of the rehabilitation program in the NoPP Group. Number of cats that have shown improvements in relationship to the parameters evaluated is reported for each follow-up.

\begin{tabular}{|c|c|c|c|c|c|c|c|c|c|}
\hline & \multicolumn{3}{|l|}{15 Days } & \multicolumn{3}{|l|}{45 Days } & \multicolumn{3}{|l|}{90 Days } \\
\hline & Tot & sw & $\begin{array}{l}\text { No } \\
\text { SW }\end{array}$ & Tot & sw & $\begin{array}{l}\text { No } \\
\text { SW }\end{array}$ & Tot & sw & $\begin{array}{l}\text { No } \\
\text { SW }\end{array}$ \\
\hline Cats & $\begin{array}{l}22 \\
(100 \%)\end{array}$ & $\begin{array}{l}3 / 22 \\
(14 \%)\end{array}$ & $19 / 22$ & $\begin{array}{l}13 \\
(59 \%)\end{array}$ & $\begin{array}{l}5 / 13 \\
(38 \%)\end{array}$ & $\begin{array}{l}8 / 13 \\
(62 \%)\end{array}$ & $\begin{array}{l}5 \\
(23 \%)\end{array}$ & $\begin{array}{l}3 / 5 \\
(60 \%)\end{array}$ & $\begin{array}{l}2 / 5 \\
(40 \%)\end{array}$ \\
\hline Muscle Tone & $\begin{array}{l}20 / 22 \\
(90 \%)\end{array}$ & $\begin{array}{l}10 / 22 \\
(45 \%)\end{array}$ & $\begin{array}{l}10 / 22 \\
(45 \%)\end{array}$ & $\begin{array}{l}13 / 13 \\
(100 \%)\end{array}$ & $\begin{array}{l}7 / 13 \\
(54 \%)\end{array}$ & $\begin{array}{l}6 / 13 \\
(46 \%)\end{array}$ & $\begin{array}{l}5 / 5 \\
(100 \%)\end{array}$ & $\begin{array}{l}3 / 5 \\
(60 \%)\end{array}$ & $\begin{array}{l}2 / 5 \\
(40 \%)\end{array}$ \\
\hline $\begin{array}{l}\text { First Limb } \\
\text { Movements }\end{array}$ & $\begin{array}{l}20 / 22 \\
(90 \%)\end{array}$ & $\begin{array}{l}10 / 22 \\
(45 \%)\end{array}$ & $\begin{array}{l}10 / 22 \\
(45 \%)\end{array}$ & $\begin{array}{l}13 / 13 \\
(100 \%)\end{array}$ & $\begin{array}{l}7 / 13 \\
(54 \%)\end{array}$ & $\begin{array}{l}6 / 13 \\
(46 \%)\end{array}$ & $\begin{array}{l}5 / 5 \\
(100 \%)\end{array}$ & $\begin{array}{l}3 / 5 \\
(60 \%)\end{array}$ & $\begin{array}{l}2 / 5 \\
(40 \%)\end{array}$ \\
\hline $\begin{array}{l}\text { Assisted } \\
\text { Walking/ } \\
\text { UWTM }\end{array}$ & $\begin{array}{l}18 / 22 \\
(81 \%)\end{array}$ & $\begin{array}{l}10 / 22 \\
(45 \%)\end{array}$ & $\begin{array}{l}8 / 22 \\
(36 \%)\end{array}$ & $\begin{array}{l}13 / 13 \\
(100 \%)\end{array}$ & $\begin{array}{l}7 / 13 \\
(54 \%)\end{array}$ & $\begin{array}{l}6 / 13 \\
(46 \%)\end{array}$ & $\begin{array}{l}5 / 5 \\
(100 \%)\end{array}$ & $\begin{array}{l}3 / 5 \\
(60 \%)\end{array}$ & $\begin{array}{l}2 / 5 \\
(40 \%)\end{array}$ \\
\hline Standing & $\begin{array}{l}10 / 22 \\
(45 \%)\end{array}$ & $\begin{array}{l}4 / 22 \\
(18 \%)\end{array}$ & $\begin{array}{l}6 / 22 \\
(27 \%)\end{array}$ & $\begin{array}{l}11 / 13 \\
(84 \%)\end{array}$ & $\begin{array}{l}7 / 13 \\
(54 \%)\end{array}$ & $\begin{array}{l}4 / 5 \\
(80 \%)\end{array}$ & $\begin{array}{l}5 / 5 \\
(100 \%)\end{array}$ & $\begin{array}{l}3 / 5 \\
(60 \%)\end{array}$ & $\begin{array}{l}2 / 5 \\
(40 \%)\end{array}$ \\
\hline $\begin{array}{l}\text { Voluntary } \\
\text { Micturition }\end{array}$ & $\begin{array}{l}0 / 22 \\
(0 \%)\end{array}$ & $\begin{array}{l}0 / 22 \\
(0 \%)\end{array}$ & $\begin{array}{l}0 / 22 \\
(0 \%)\end{array}$ & $\begin{array}{l}0 / 13 \\
(0 \%)\end{array}$ & $\begin{array}{l}0 / 13 \\
(0 \%)\end{array}$ & $\begin{array}{l}0 / 13 \\
(0 \%)\end{array}$ & $\begin{array}{l}0 / 5 \\
(0 \%)\end{array}$ & $\begin{array}{l}0 / 5 \\
(0 \%)\end{array}$ & $\begin{array}{l}0 / 5 \\
(0 \%)\end{array}$ \\
\hline
\end{tabular}

\section{No SW cats}

At the end of the rehabilitation program, of the 22 cats of the NoPP group, twelve (55\%) did not develop an autonomous spinal locomotion. On admission, crossed extensor reflex was observed in 6 cats (50\%). Detailed data are shown in Tables 4 and 5.

\section{SW cats}

At the end of the treatment, of the 22 cats of the NoPP group, ten cats (45\%) developed autonomous spinal locomotion (SW). (Tables 4 and 5).

At 15 days, three cats achieved SW and were discharged. At 45 days, five further cats achieved autonomous spinal locomotion. Five cats underwent physical therapy for 90 days and three of them (60\%) acquired autonomous spinal locomotion at the end of the rehabilitation period.

On admission, crossed extensor reflex was observed in eight cats (80\%) and resulted significantly associated with the acquisition of SW $(p=0.008)$.

Improvement in assisted walking/UWTM was found to be significantly associated with higher possibility to achieve SW at the end of the treatment $(p=0.04)$. 
There was no significant association between the duration of the rehabilitation program and the acquisition of SW.

Breed, sex, age, BCS, type of lesion, full-time hospitalization, surgical treatment and presence of voluntary micturition at the time of presentation were not found to be correlated with the acquisition of SW.

\section{Control Group}

The control group included seven cats. Absence of pelvic limb PP was observed in four patients (57\%). Four cats $(57 \%)$ were affected by spinal trauma, while disc herniation and contusive/hemorrhagic lesions were reported, respectively, in one (14\%) and two $(29 \%)$ cats. At the time of presentation, six patients $(86 \%)$ were paraplegic whilst another one $(14 \%)$ showed non-ambulatory paraparesis. Incompetent bladder was reported in six cats $(86 \%)$. None of the cats regained voluntary micturition or ambulatory condition after at home exercises.

When comparing cats that underwent the rehabilitation program and the control group, accomplishment of an intensive rehabilitation program was significantly associated with a higher possibility to regain functional locomotion $(p=0.005)$. Recovery of voluntary micturition did not show significant differences among the control group and the cats that underwent physical therapy.

\section{Discussion}

Physiotherapy is increasingly considered a part of crucial importance of the treatment of dogs with SC injuries and is nowadays increasingly performed also in cats.

To the best authors' knowledge, this is the first field study describing the physiotherapy treatment in cats suffering from not experimentally induced acute SC injury.

In accordance with what is reported for dogs under field conditions, our result found a positive association between maintenance of pelvic limbs PP and functional recovery of voluntary locomotion and micturition in the study population $[12,13]$. Elicit of PP in pelvic limbs can be considered a clinical indicator of the residual integrity of the spinal cord and, according to feline literature, its presence can be associated with a better outcome than its absence [14].

Literature data are the result of experimental studies showing that for incomplete spinal cord injuries (SCl) a positive outcome was associated with training regimens involving partial weight-bearing activity, started within a critical period of 1-2 weeks after $\mathrm{SCl}$ and maintained for at least 8 weeks [9]. Our cat population, for obvious reasons, started physiotherapy in a much wider range of time after injury and, the time between the onset of neurological signs and the beginning of the physiotherapy did not influence the outcome. This observation should be considered cautiously due to the limited number of patients.

None of the cats with PP in the control group regained the ability to walk and, when comparing the cats (PP group and NoPP group) that underwent intensive physiotherapy treatment and the control group, 
completion of an intensive rehabilitation program was significantly associated with a higher possibility to regain functional locomotion.

The recovery of voluntary micturition did not show significant differences among the control group and the cats that underwent physiotherapy (PP group and NoPP group). Unfortunately, the limited number of cases in the control group prevents to draw relevant conclusions.

At the end of the physiotherapy treatment, ten cats (45\%) without PP developed SW. Despite the popular opinion that a poor prognosis is associated with the absence of PP, many studies reported the possibility of achievement of a spinal involuntary reflex gait and some authors described this type of locomotion also under field condition in dogs $[5,12]$. To the authors' knowledge, SW was described in cats only in experimental contexts and our data showed the acquisition of SW in almost half of the study population under natural conditions. Noticeably, all these cats belonged to the group that underwent intensive physiotherapy.

Crossed extensor reflex was associated with acquisition of SW and relevant improvement observed in assisted walking/UWTM during the first 15 days was found to be associated with a higher possibility to achieve SW at the end of the treatment. Such information might be helpful for the physiotherapist and the neurologist in the early identification of potential candidates in developing SW, avoiding waste of time, money and useless hopes for the owner. Prospective studies are necessary to further investigate and confirm these preliminary observations.

Most cats were presented with dramatic ambulatory deficits and no association was found between clinical presentation and final outcome. Considering that in the control group, characterized by the absence of an intensive physiotherapy treatment, none of the patients recovered motor function, we can cautiously hypothesize that physiotherapy could represent an effective tool in improving outcome, independently from the severity of neurological signs. Physiotherapy could play an important role in supporting the restoration of motor function, modeling and promoting the so-called "plasticity" of the spinal cord [15]. In an experimental scenario, several studies that had a control group of cats not undergoing treadmill training following the injury, demonstrated how the exercise produced better recovery in terms of maximum speed and number of steps taken on the treadmill $[7,8]$, greater articular excursion and more symmetrical gait $[8,16]$.

In accordance with the literature, the most frequent spinal disorder reported in our population was a traumatic external injury. Disk disease, one of the most represented causes of acute $\mathrm{SCl}$ in dogs, is much less common in cats $[17,18]$, possibly due to the minor degree of feline disc degeneration [19].

In this study, $42 \%$ of cats that underwent a physiatry examination, did not receive intensive physical therapy because of the owner's rejection, possibly due to the perceived difficulties in managing feline patients that may not cooperate as dogs do, especially in hydrotherapy sessions [20]. All cats underwent physiotherapy without too many difficulties because different protocols were established according to the cat's behavior. Only docile cats were immediately submitted to aggressive physiotherapy, including 
hydrotherapy, while for more frightened or aggressive cats a much more slowly progressive treatment regimen was provided. As abovementioned, progressive exposure to water, made anxious cats increasingly confident within a few days. In our experience, full-time hospitalization was not associated to better recover of locomotion, leading to the conclusion that in patients adequately followed at home, the rehabilitation protocol can be achieved successfully also in a day-hospital regimen, helping the owner in terms of cost abatement and reducing the stress for the cats.

The present study has several limitations and caution must be used in the interpretation of results obtained from a small number of animals, possibly not reflecting the reliability of the data and therefore decreasing the power of statistical analysis. The retrospective nature of this study did not allow us to have a homogeneous sample in terms of group distribution and timing in the start of physiotherapy and this could have possibly produced biased data. In particular, the small number of cats in the control group may not reflect the trustworthiness of the results. Nevertheless, authors are confident that these preliminary results may represent an interesting starting point for prospective studies enrolling a larger number of cats.

\section{Conclusion}

As previously described in dogs, also in cats with severe acute TL lesion recovery can benefit from intensive physiotherapy. The present experience demonstrates that, in case of loss of PP, the acquisition of SW is possible also under field condition in a relevant percentage of cases. Nevertheless, the owners should be informed of the high possibility of persistent incompetent bladder and its necessity of lifelong manual expression. This study provides some preliminary suggestions for further prospective investigation about the use of prognostic indicators such as crossed extensor reflex and early movements seen in UWTM, to allow improvement in predicting the outcome of severe TL conditions.

\section{Declarations}

\section{Author Contributions}

All authors helped to draft the manuscript and participated in its design. AG, TAK, MM collected, analyzed and interpreted the data. LD collected, analyzed and interpreted the data concerning the physiotherapy. GG provided critical manuscript revising and coordinated the study. MM performed the statistics. SDM developed the figure and the tables. All authors read and approved the manuscript.

\section{Conflict of Interest}

The authors declared no potential conflicts of interest with respect to the research, authorship, and/or publication of this article.

\section{Funding}


The authors received no financial support for the research, authorship, and/or publication of this article.

\section{Ethical Approval}

This work involved the use of non-experimental animals only (including owned or unowned animals and data from prospective or retrospective studies). Established internationally recognized high standards ('best practice') of individual veterinary clinical patient care were followed. Ethical approval from a committee was therefore not necessarily required.

\section{Informed Consent statement}

Informed consent (either verbal or written) was obtained from the owner or legal custodian of all animal(s) described in this work (either experimental or non-experimental animals) for the procedure(s) undertaken (either prospective or retrospective studies).

\section{Informed consent for publication statement}

No animals or humans are identifiable within this publication, and therefore additional informed consent for publication was not required.

\section{Availability of data and materials}

The data recorded and analyzed during this study are available from the corresponding author upon reasonable request

\section{References}

1. Drum MG, Bockstahler B, Levine D, et al. Feline Rehabilitation. Vet Clin North Am Small Anim Pract 2015; 45(1): 185-201.

2. Draper WE, Schubert TA, Clemmons RM, et al. Low-level laser therapy reduces time to ambulation in dogs after hemilaminectomy: a preliminary study. J Small Anim Pract. 2012;53(8):465-9.

3. Hady LL, Schwarz PD. Recovery times for dogs undergoing thoracolumbar hemilaminectomy with fenestration and physical rehabilitation: a review of 113 cases. J Vet Med Anim Health. 2015;7(8):278-89.

4. Bennaim $M$, Porato $M$, Jarleton $A$, et al. Preliminary evaluation of the effects of photobiomodulation therapy and physical rehabilitation on early postoperative recovery of dogs undergoing hemilaminectomy for treatment of thoracolumbar intervertebral disk disease. Am J Vet Res. 2017;78(2):195-206.

5. Gallucci A. Dragone L, Menchetti M, et al. Acquisition of Involuntary Spinal Locomotion (Spinal Walking) in Dogs with Irreversible Thoracolumbar Spinal Cord Lesion: 81 Dogs. J Vet Intern Med 2017; 31(2): 492-7. 
6. Zidan N, Sims C, Fenn J, et al. A randomized, blinded, prospective clinical trial of postoperative rehabilitation in dogs after surgical decompression of acute thoracolumbar intervertebral disc herniation. J Vet Intern Med. 2018;32(3):1133-44.

7. Lovely RG. Gregory RJ, Roy RR, et al. Effects of training on the recovery of full-weight-bearing stepping in the adult spinal cat. Exp Neurol 1986; 92(2): 421-35.

8. De Leon RD. Hodgson JA, Roy RR, et al. Locomotor Capacity Attributable to Step Training Versus Spontaneous Recovery After Spinalization in Adult Cats. J Neurophysiol 1998; 79(3): 1329-40.

9. Battistuzzo CR. Callister RJ, Callister R, et al. A Systematic Review of Exercise Training to Promote Locomotor Recovery in Animal Models of Spinal Cord Injury. J Neurotrauma 2012; 29(8):1600-13.

10. Edgerton VR, Tillakaratne NJK, Bigbee AJ, et al. Plasticity of the Spinal Neural Circuitry After Injury. Annu Rev Neurosci. 2004;27(1):145-67.

11. Kiehn O. Locomotor Circuits in the Mammalian Spinal Cord. Annu Rev Neurosci. 2006;29((1):):279306.

12. Olby N. Levine J, Harris T, et al. Long-term functional outcome of dogs with severe injuries of the thoracolumbar spinal cord: 87 cases (1996-2001). J Am Vet Med Assoc 2003; 222(6): 762-9.

13. Skytte $D$, Schmokel $H$. Relationship of preoperative neurologic score with intervals to regaining micturition and ambulation following surgical treatment of thoracolumbar disk herniation in dogs. $J$ Am Vet Med Assoc 2018; July 15, Vol. 253, 196-200

14. Grasmueck S, Steffen F. Survival Rates and Outcomes in Cats with Thoracic and Lumbar Spinal Cord Injuries Due to External Trauma. J Small Anim Pract. 2004;45((6):):284-8.

15. Barrière G. Leblond $\mathrm{H}$, Provencher J, et al. Prominent Role of the Spinal Central Pattern Generator in the Recovery of Locomotion after Partial Spinal Cord Injuries. J Neurosci 2008; 28(15): 3976-87.

16. Rossignol S. Locomotion and its recovery after spinal injury. Curr Opin Neurobiol. 2000;10((6):):70816.

17. Muñana KR. Olby NJ, Sharp NJ, et al. Intervertebral disk disease in 10 cats. J Am Anim Hosp Assoc 2001; 37(4): 384-9.

18. Gonçalves R, Platt SR, Llabrés-Díaz FJ, et al. Clinical and Magnetic Resonance Imaging Findings in 92 Cats with Clinical Signs of Spinal Cord Disease. J Feline Med Surg 2009; 11(2): 53-59.

19. Smolders L. Ettinger-Ferguson L, Grinwis G, et al. Preliminary investigation of the feline intervertebral disc. Proceedings of the 27th Symposium ESVN-ECVN. J Vet Int Med 2015; 29(5): 1445-1446..

20. Sharp B. Feline Physiotherapy and Rehabilitation: 1. Principles and potential. J Feline Med Surg. 2012;14(9):622-32.

\section{Figures}




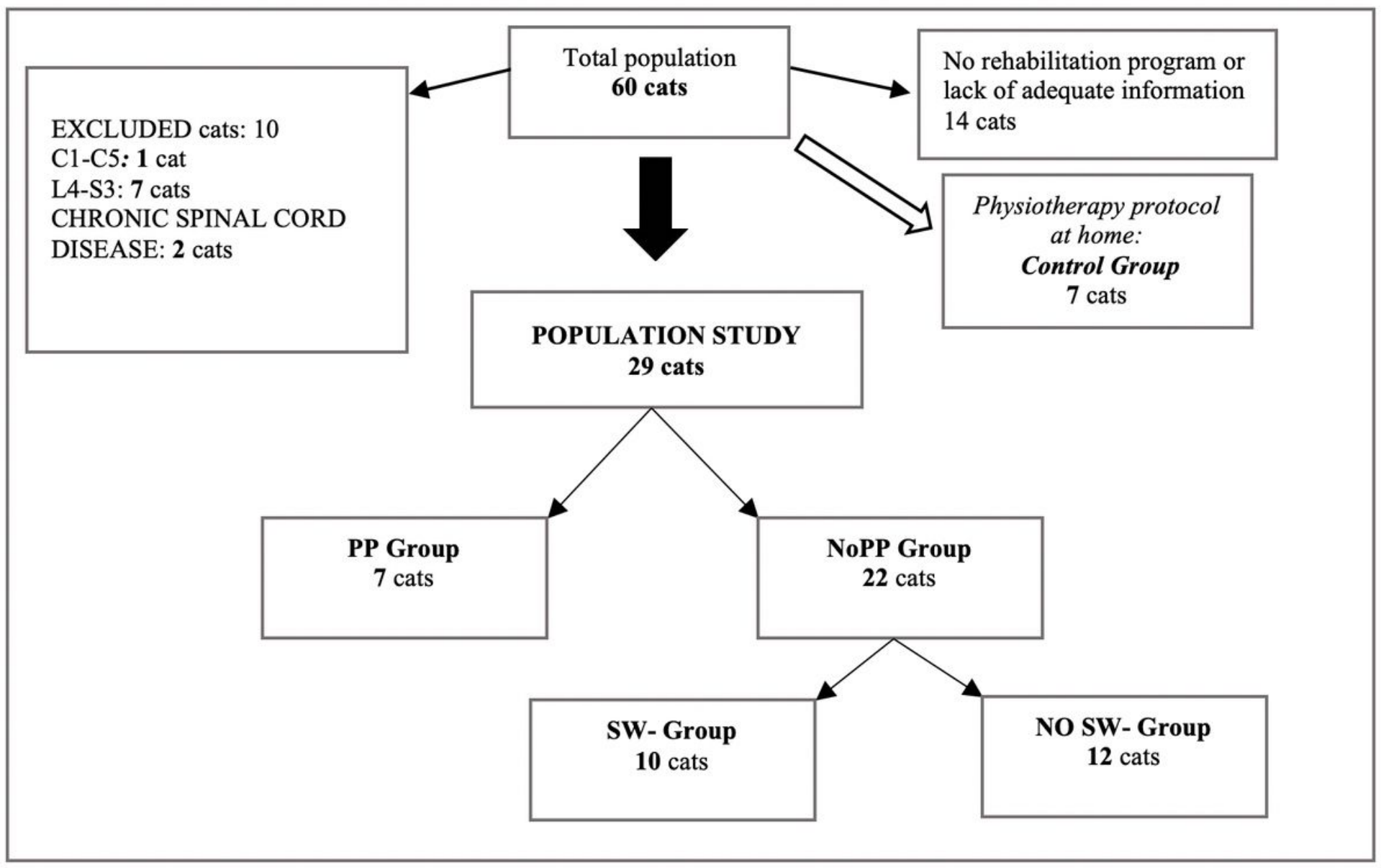

Figure 1

Selection of Cat population 